\title{
A Typology of Sick-Listed Claimants to Improve Communication Skills for Social Insurance Physicians during Medical Disability Assessment Interviews
}

\author{
H. J. van Rijssen • A. J. M. Schellart • \\ J. R. Anema • A. J. van der Beek
}

Published online: 10 July 2010

(C) Springer Science+Business Media, LLC 2010

\begin{abstract}
Introduction Role play with standardised simulated patients is often included in communication training. However, regarding physician-patient encounters in medical disability assessment interviews it is unclear what should be included in the scenarios for actors. The first objective of this study was to determine which types of medical disability claimants can be distinguished based on behavioural determinants. The second objective was to determine if these types of claimants differed in their perception of communication behaviour and their satisfaction with the communication with physicians. Methods Questionnaire data were collected from 56 Dutch claimants for 13 behavioural determinants before their assessment interview, and for 12 behavioural and satisfaction variables afterwards. For the first objective cluster analyses were performed and for the second objective linear regression analyses were performed. Results The results showed that three types of claimants could be distinguished: insecure support-seeking claimants, confident claimants, and socially isolated claimants. Overall, claimants were positive about the communication with the physician: insecure support-seeking claimants were satisfied and confident claimants were highly satisfied, but socially isolated claimants were unsatisfied. Conclusion Scenarios for
\end{abstract}

H. J. van Rijssen · A. J. M. Schellart · J. R. Anema .

A. J. van der Beek $(\bowtie)$

Department of Public and Occupational Health, EMGO Institute for Health and Care Research, VU University Medical Center, Amsterdam, The Netherlands

e-mail: a.vanderbeek@vumc.nl

H. J. van Rijssen · A. J. M. Schellart · J. R. Anema .

A. J. van der Beek

Research Center for Insurance Medicine, collaboration between AMC-UMCG-UWV-VUmc, Amsterdam, The Netherlands standardised simulated patients should include different types of claimants. In training, special attention should be given to communication with socially isolated claimants.

Keywords Communication - Satisfaction - Typology · Work disability assessment interview .

Medical disability claimants - Social insurance medicine

\section{Introduction}

In many communication skills training courses for physicians role play is used to practise skills or evaluate performance. A recent overview of systematic reviews even showed that role play, especially combined with feedback about performance, is an effective strategy to teach communication skills to physicians [1]. In simulation-based medical education, scenarios for standardised patients need to be provided. These scenarios should contain realistic patient descriptions with detailed information about important personal characteristics relevant for communication behaviour. However, it is unclear which of these characteristics are the most important in physician-patient encounters. Furthermore, knowing the relationship between satisfaction with communication behaviour and patient characteristics allows a better founded choice of which feedback actors should provide. This could increase the effectiveness of learning about the influence of the physician's communication (i.e. the two-directional exchange of verbal and non-verbal information) in physician-patient encounters.

Medical disability assessment interviews are an example of physician-patient encounters. These interviews are an important step in determining whether a patient with prolonged absence from work due work disability (i.e. a 
claimant) is entitled to a work disability pension/social security benefits because of long term disability. National practices may vary considerably, but there are several basic principles. In the Netherlands, where the current study was conducted, assessment interviews for long-term work disability are performed after 2 years of sick leave, when a claimant applies for a long-term disability benefit. A social insurance physician performs the face-to-face interviewgenerally a one-time encounter between that physician and that claimant-to collect the information necessary to assess work capacity and eligibility for a benefit. Usually, also information from other professionals (e.g. occupational physician, specialists) is available to the social insurance physician [2-4].

In addition to the physician's communication behaviour, the personal characteristics of the claimant might influence the communication during these assessment interviews as well. For example, studies have shown that the communication style of patients with a high socio-economic status is more active and affective, and elicits more information from physicians [5], and that the behaviour of patients influences the way physicians communicate with them [6]. This implies that, although each claimant has unique characteristics and disabilities, claimant behaviour is alike on certain aspects as well. These aspects could be demographic characteristics, such as gender or social class, but also more profound characteristics, such as expectations about the assessment interview or personality. Knowing in advance which claimant behaviour will likely be encountered, might thus make it easier to determine how to communicate with the claimant.

The first objective of this study was to determine which types of medical disability claimants could be distinguished based on behavioural determinants. The second objective was to determine: (2a) if these types of claimants differ in their perception of the communication behaviour of the social insurance physician during a recently attended medical disability assessment interview; and (2b) if these types of claimants differ in their satisfaction with the communication with the social insurance physician.

\section{Materials and Methods}

\section{Data Collection and Subjects}

Data were collected between March and July 2008. Approximately 360 claimants of 36 social insurance physicians (10 per physician) were sampled by the Dutch Institute of Employee Benefit Schemes, the national administrative body for employee benefits. Inclusion criteria for participants were: being invited for a medical disability assessment interview according to the Work
Disability Benefits Acts after a minimum of 2 years of sick leave, and being able to attend this assessment interview at an office of the Institute of Employee Benefit Schemes. Exclusion criteria were: being employed by the Institute of Employee Benefit Schemes, living abroad, and insufficient skills in the Dutch language to participate in the study. Data were self-reported and collected at two successive moments in time: shortly before and after the assessment interview.

Potential participants received a letter with explanations of the study. Upon their decision to participate they filled in an informed consent form and completed the first questionnaire. Participants were asked to return the questionnaire prior to attending the assessment interview, and they subsequently received a second questionnaire by mail. This second questionnaire was completed shortly after they had returned from the assessment interview. After the official deadline for complaints and objections about the disability assessment had passed, it was checked if the participants had filed a complaint about the communication with the social insurance physician and if they had objected to the decision regarding social security benefits.

Written informed consent was obtained from all participants. The study was approved by the scientific committee of the EMGO Institute for Health and Care Research of the VU University Medical Center and by the Institute of Employee Benefit Schemes. Medical ethical approval was not needed according to the Dutch law.

\section{Measures}

A modified Attitude/Social influence/self-Efficacy model (ASE model [7]), an adapted version of the Theory of Planned Behaviour $[8,9]$, provided a theoretical framework for this study. The first questionnaire included questions about intentions with regard to behaviour, attitudes, social influence, self-efficacy, skills, obstacles, and support concerning the claimants' communication with physicians in general and with social insurance physicians in particular. Answers were given on 4-point Likert scales. The second questionnaire included questions about the perception of and satisfaction with the communication behaviour of the physician during the assessment interview. Answers were given on 5-point Likert scales. Because some questions and scales had to be adjusted to the context of the disability assessment interview, the questionnaires were pilot tested for relevance, comprehensibility, and length. This was done in two phases. Firstly, three claimants who had recently attended an assessment interview completed the questionnaires speaking out loudly about their thoughts and the questionnaire was adjusted according to their remarks. Secondly, the adjusted questionnaire and accompanying letter, 
Table 1 Constructs and their scales_-derived from the ASE model—included in the questionnaires, with the number of items (\#), reliability of the scales (Cronbach's Alpha; $\alpha$ ), median of the scores $(\mathrm{Md})$, mean scores $(M)$, standard deviations (SD) and ranges

\begin{tabular}{|c|c|c|c|c|c|c|c|}
\hline Construct & Scales $^{3}$ & \# & $\alpha$ & Md & $M$ & $\mathrm{SD}$ & Range \\
\hline \multirow[t]{3}{*}{ Intentions } & Strategic planning in preparation (a) & 4 & 0.82 & 2.00 & 2.11 & 0.71 & $1.00-4.00$ \\
\hline & Avoidance in preparation (a) & 5 & 0.65 & 2.20 & 2.25 & 0.57 & $1.00-4.00$ \\
\hline & Accepting social support in preparation (a) & 3 & 0.68 & 2.00 & 2.23 & 0.76 & $1.00-4.00$ \\
\hline \multirow[t]{4}{*}{ Attitudes } & Passive problem solving in preparations (b) & 3 & 0.75 & 1.86 & 1.85 & 0.61 & $1.00-3.29$ \\
\hline & Expressing emotions in preparation (b) & 7 & 0.79 & 2.00 & 1.99 & 0.54 & $1.00-4.00$ \\
\hline & Active problem solving in preparation (b) & 7 & 0.78 & 2.43 & 2.40 & 0.53 & $1.14-3.71$ \\
\hline & Expectations about the communication $(\mathrm{c})^{1}$ & 6 & 0.69 & 3.67 & 3.64 & 0.63 & $2.33-4.67$ \\
\hline Social influence & Social influence of acquaintances in preparation (d) & 7 & 0.70 & 2.14 & 2.12 & 0.72 & $1.00-3.57$ \\
\hline \multirow[t]{2}{*}{ Self-efficacy } & Emotional self-efficacy (e) & 5 & 0.90 & 2.80 & 2.58 & 0.88 & $1.20-4.00$ \\
\hline & Instrumental self-efficacy (f) & 10 & 0.92 & 2.55 & 2.47 & 0.69 & $1.00-4.00$ \\
\hline Skills & Expected skills for the interview $(\mathrm{g})^{1}$ & 7 & 0.95 & 3.00 & 3.13 & 0.90 & $1.50-5.00$ \\
\hline Obstacles & Obstacles in the interview (c) ${ }^{1}$ & 5 & 0.69 & 2.20 & 2.25 & 0.79 & $1.00-4.20$ \\
\hline Support & Support from other people (c) & 5 & 0.80 & 2.90 & 2.88 & 0.87 & $1.00-4.00$ \\
\hline \multirow[t]{4}{*}{ Behaviour } & Expression of opinions about work abilities $(\mathrm{h})^{2}$ & 5 & 0.76 & 2.00 & 2.06 & 0.65 & $1.00-3.00$ \\
\hline & Listening behaviour of social insurance physician $(h, i)$ & 3 & 0.86 & 5.00 & 4.45 & 0.85 & $1.00-5.00$ \\
\hline & Claimant filed a complaint about the assessment & - & - & - & - & - & - \\
\hline & Claimant objected to outcome of assessment & - & - & - & - & - & - \\
\hline \multirow[t]{8}{*}{ Satisfaction with behaviour } & Way of information exchange (h) & 5 & 0.94 & 4.00 & 3.73 & 1.00 & $1.00-5.00$ \\
\hline & Competence of the social insurance physician $(\mathrm{j}, \mathrm{k})$ & 5 & 0.89 & 4.00 & 3.86 & 1.05 & $1.00-5.00$ \\
\hline & Satisfaction with relationship (j) & 7 & 0.94 & 4.00 & 3.76 & 1.07 & $1.00-5.00$ \\
\hline & Trust in the medical assessment (1) & 1 & - & 4.00 & 3.71 & 1.49 & $1.00-5.00$ \\
\hline & Correctness of expectations about communication $(\mathrm{k})$ & 1 & - & 4.00 & 3.42 & 1.51 & $1.00-5.00$ \\
\hline & Satisfaction with communication $(\mathrm{k})$ & 1 & - & 5.00 & 3.91 & 1.46 & $1.00-5.00$ \\
\hline & Satisfaction with information (1) & 1 & - & 4.00 & 4.04 & 1.14 & $1.00-5.00$ \\
\hline & Satisfaction with atmosphere (1) & 1 & - & 5.00 & 4.13 & 1.26 & $1.00-5.00$ \\
\hline
\end{tabular}

${ }^{1}$ Items in these scales were answered on a 5-point scale instead of a 4-point scale

${ }^{2}$ Items in these scales were answered on a 3-point scale instead of a 5-point scale

3 (a) WCQ: Ways of Coping Questionnaire [15]; (b) UCL: Utrecht Coping List [16]; (c) Questions formulated by ourselves, based on different sources, including other questionnaires and behavioural observations during assessment interviews; (d) Based on the COPE Questionnaire [17]; (e) STAI: State-Trait Anxiety Inventory [18]; (f) GSE: General Self-Efficacy Scale [19]; (g) Pearlin Mastery Scale [20]; (h) Questions of Croon and Langius [21]; (i) AStri Client Monitor of the Institute of Employee Benefit Schemes [22]; (j) PDRQ-9: Patient-Doctor Relationship Questionnaire [23]; (k) Patient Satisfaction with Occupational Health Questionnaire [24, 25]; (1) Questions of Nauta [26, 27]

information brochure, and informed consent form were completed by three members of the Dutch national claimants' counsel and systematically discussed with them. Taking their findings into account, the final version of the questionnaires was established.

To prepare the data for analysis, items were combined into scales with an extended item-total procedure in SPSS 15.0, in which the items were correlated with their scale total and with the totals of all of the other scales ([10]; p. 96). This resulted in four scales of attitudes, three of intentions with regard to behaviour, two of self-efficacy, and one of social influence, skills, obstacles, and support. For the second questionnaire the procedure resulted in two scales of behaviour and three of satisfaction with behaviour. Additionally, two behavioural variables were added (i.e. whether or not a complaint had been filed and whether or not the claimant objected to the assessment outcome), as well as five satisfaction variables. For all variables a high score meant the construct was present and a low score meant the construct was absent. An overview is presented in Table 1.

\section{Data Analysis}

Because no data were available for a non-response analysis, we studied whether the participants were a representative sample of the claimants that completed the first questionnaire and of all approached claimants. To this end Mann-Whitney $U$ tests were performed.

For the first objective standardised, Z-transformed data were analysed with hierarchical cluster analysis using Ward's method (clustering by claimants), followed by nonhierarchical K-means cluster analysis with the number of 
clusters and initial cluster centres taken from the hierarchical cluster analysis. For validation, the final results were compared to those of K-means clustering with random initial cluster centres [11]. All scales indicating intentions with regard to behaviour, attitudes, social influence, selfefficacy, skills, obstacles, and support were included.

For the second objective linear regression analyses were performed with the measures of claimants' perception of communication behaviour (objective 2a) and claimants' satisfaction with the communication with social insurance physicians (objective 2b) as dependent variables, and the claimant type as independent variable. Adjustments for confounding and effect modification (interaction effects with claimant type) were made when necessary. Based on the literature, the following background variables were considered potential confounders (over 10\% change of the regression coefficient) or effect modifiers $(P<0.05)$ : age, gender, level of education, number of attended assessment interviews, main diagnosis (self-reported), functional capacity for work (according to the social insurance physician). For all analyses SPSS 15.0 was used.

\section{Results}

\section{Participants}

The personal characteristics of the participants are summarised in Table 2, as well as those of the claimants who participated in the first questionnaire and those of all claimants who were approached for the survey. A total of 63 participants who lived scattered over the Netherlands, completed the first questionnaire (17.5\%). Of them $56(88.9 \%)$ also completed the second questionnaire, and were included in this study. Their mean age was 48.1 years $(\mathrm{SD}=8.9$; range $=22-62$ ) and $55.4 \%$ were female. The assessment interviews of these 56 claimants were performed by 28 social insurance physicians. The mean age of these physicians was 50 years and 2 months ( $\mathrm{SD}=7$ years and 2 months). Of them, $39.3 \%$ was female and $60.7 \%$ percent male. On average, they had worked as an insurance physician in practice for 15 years and 9 months $(S D=7$ years and 10 months) and at that moment they were working for $31.6 \mathrm{~h}$ $(\mathrm{SD}=10.0 \mathrm{~h})$ per week as an insurance physician.

No differences were found between the participants in this study who completed both questionnaires $(N=56)$ and the claimants who completed only the first questionnaire $(N=63)$. The participants in this study $(N=56)$ differed significantly from all claimants who were approached for the survey $(N=298)$ on assessment type and age group. No differences were found on the other background variables. A lower percentage of participants was invited to a first time assessment and thus a higher percentage to a second or subsequent assessment, than all approached claimants. On average, participants were older than all approached claimants. Claimants for a subsequent assessment and older claimants thus seemed more willing to participate in the study.

\section{Objective 1: Types of Claimants}

One outlier was identified and excluded from analysis. The results of the cluster analyses showed that a three cluster classification was the best claimant classification. Because
Table 2 Mean percentages for the distributions of personal characteristics (age, gender, assessment type, main diagnosis) of the participants of the complete study, the claimants that completed the first questionnaire, and all approached claimants
* Group differed on this variable from the group of participants $(P<0.05)$

\# Unknown

\begin{tabular}{|c|c|c|c|}
\hline & $\begin{array}{l}\text { Participants } \\
(N=56)\end{array}$ & $\begin{array}{l}\text { Claimants first } \\
\text { questionnaire } \\
(N=63)\end{array}$ & $\begin{array}{l}\text { All approached } \\
\text { claimants } \\
(N=298)\end{array}$ \\
\hline Age (years) $[95 \% \mathrm{CI}]$ & $48.1[45.7 ; 50.5]$ & $48.1[45.9 ; 50.2]$ & \# \\
\hline Age group $(\%)$ : & & & $*$ \\
\hline Up to 44 years & 21.4 & 22.2 & 39.6 \\
\hline $45-54$ years & 57.1 & 58.7 & 47.3 \\
\hline 55 years and over & 21.4 & 19.0 & 13.1 \\
\hline \multicolumn{4}{|l|}{ Gender $(\%)$ : } \\
\hline Male & 44.6 & 42.9 & 47.0 \\
\hline Female & 55.4 & 57.1 & 53.0 \\
\hline Assessment type (\%): & & & $*$ \\
\hline First time assessment & 33.9 & 36.5 & 51.0 \\
\hline Subsequent time & 66.1 & 63.5 & 49.0 \\
\hline \multicolumn{4}{|l|}{ Main diagnosis (\%): } \\
\hline Musculoskeletal & 28.6 & 30.2 & 29.9 \\
\hline Psychological & 28.6 & 28.6 & 33.6 \\
\hline Cardiovascular & 8.9 & 7.9 & 6.7 \\
\hline Mix or other & 33.9 & 33.3 & 29.9 \\
\hline
\end{tabular}


Table 3 The final cluster centres for each scale (standardised by

Z-transformation) and statistical significances of the cluster differences $(P<0.05)$ for the final three cluster solution $(N=55)$

\# Type A = insecure supportseeking claimants; Type

$\mathrm{B}=$ confident claimants; Type

$\mathrm{C}=$ socially isolated claimants

\begin{tabular}{llrrrr}
\hline Construct & Scales & \multicolumn{2}{c}{ Final cluster centres ${ }^{\#}$} & \multicolumn{2}{c}{$P$} \\
\cline { 3 - 5 } & & Type A & Type B & Type C & \\
\hline \multirow{2}{*}{ Intentions } & Strategic planning & 0.64 & -0.46 & -0.32 & $<\mathbf{0 . 0 0 1}$ \\
& Avoidance & -0.01 & -0.17 & 0.07 & 0.734 \\
& Accepting social support & 0.69 & -0.32 & -0.61 & $<\mathbf{0 . 0 0 1}$ \\
Attitudes & Passive problem solving & 0.39 & -0.72 & 0.56 & $<\mathbf{0 . 0 0 1}$ \\
& Expressing emotions & 0.13 & -0.27 & 0.06 & 0.348 \\
& Active problem solving & -0.10 & 0.26 & -0.31 & 0.238 \\
Social influence & Social influence of acquaintances & 0.59 & -0.50 & -0.12 & $<\mathbf{0 . 0 0 1}$ \\
Self-efficacy & Emotional self-efficacy & -0.69 & 0.74 & -0.23 & $<\mathbf{0 . 0 0 1}$ \\
& Instrumental self-efficacy & -0.56 & 0.58 & -0.05 & $<\mathbf{0 . 0 0 1}$ \\
Skills & Expected skills for the interview & -0.79 & 0.70 & -0.24 & $<\mathbf{0 . 0 0 1}$ \\
Obstacles & Support from other people & 0.69 & 0.10 & -1.08 & $<\mathbf{0 . 0 0 1}$ \\
& Obstacles in the interview & 0.43 & -0.84 & 0.83 & $<\mathbf{0 . 0 0 1}$ \\
\hline
\end{tabular}

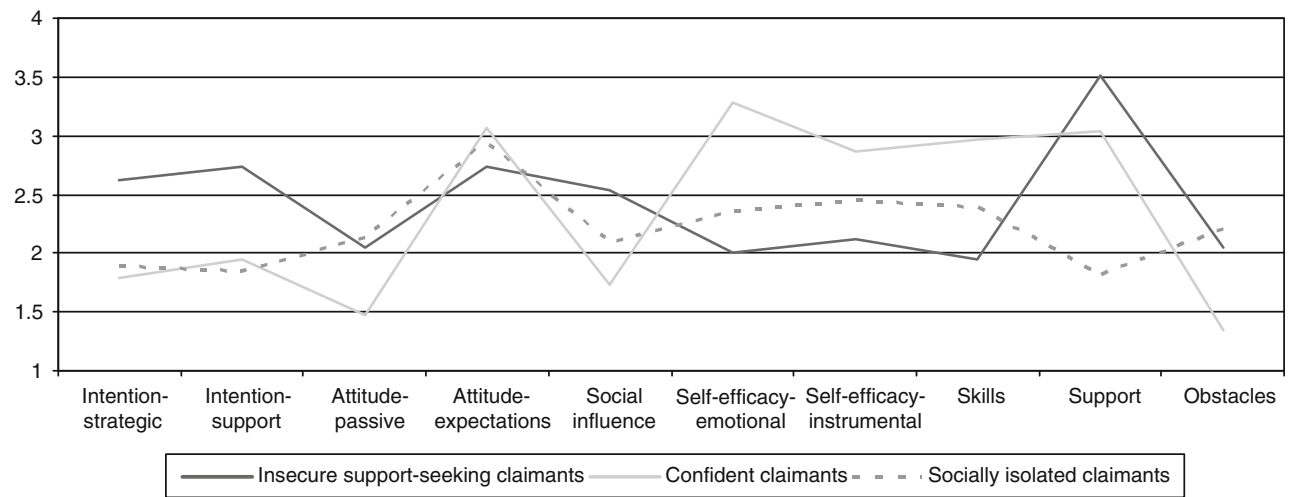

Fig. 1 Mean standardised scores of the claimants $(N=55)$ on the scales that differed significantly $(P<0.05)$ for the three cluster solution (possible range: $1-4$ )

some variables were somewhat skewed, analyses were replicated with those variables log-transformed. These analyses gave similar results. The three cluster solution is presented in Table 3 and in Fig. 1. The results showed: (A) a cluster of constructively preparing claimants with negative expectations and adequate social support, named the insecure support-seeker (34.5\% of the claimants); (B) a cluster of positively minded claimants with a non-passive coping pattern, named the confident $(41.8 \%$ of the claimants); and (C) a cluster of moderately able and indecisiveness claimants, who lack social support, named the socially isolated (23.6\% of the claimants). More in detail, these types of claimants could be described as follows:

- Insecure support-seeking claimants had negative expectations about themselves, the social insurance physician, and the assessment interview (low scores on emotional and instrumental self-efficacy and on skills, high scores on obstacles). Their intentions to accept social support and the availability of social support from other people were high, although they reported only average influence of others. The passivity of their coping attitude was average to low (i.e. they had moderate to little inclination to isolate themselves, withdraw, or ruminate) and their preparation for the interview (an intention measure) was relatively strategic.

- Confident claimants were characterised by overall high expectations about themselves, the social insurance physicians and the assessment interview (high scores on emotional and instrumental self-efficacy and skills, low scores on obstacles). Although social support was reasonably to highly available to these claimants, they reported low intentions to accept social support and little influence from others. They had a lack of passive coping attitude (e.g. they were not inclined to isolate themselves, withdraw or ruminate) and had little intentions for strategic planning in preparation for the interview. 
- Socially isolated claimants were characterized by indecisiveness in their expectations (i.e. they were hesitant or undecided in their opinion about the assessment interview; their views can be described as moderate, subdued, or not extreme). Their emotional and instrumental self-efficacy, skills, and obstacles were average. Intentions to accept social support, social influence, and availability of support from others were all small. These claimants had an average to low passive coping attitude and low intentions for strategic planning.

Objective 2: Relationship with Behaviour and Satisfaction

An overview of the predictive validity of the three claimant types for perceived behaviour during and for satisfaction with the assessment interview, taking confounders and effect modifiers into account, is presented in Table 4. Below, the results for the adjusted analyses are presented.

The adjusted analyses showed no overall differences between the three types of claimants on their perception of communication behaviour and on their satisfaction. On three variables differences were found at $P<0.10$ : expression of opinions about work abilities $(P=0.063)$, listening behaviour $(P=0.057)$, and satisfaction with the information exchange $(P=0.061)$.

Significant differences between two claimant types did exist. On all three variables just mentioned socially isolated claimants differed from confident claimants, with the former having a low and the latter a high level of satisfaction compared to the mean score $(P=0.008, P=0.007$, and $P=0.051$, respectively). About the expression of opinions about work abilities socially isolated claimants also were more negative than insecure support-seeking claimants $(P=0.011)$. One other difference was found: insecure support-seeking claimants differed significantly from confident claimants in that the first were unsatisfied while the latter were satisfied about the degree to which their expectations about the communication were met $(P=0.032)$. Summarising, insecure support-seeking claimants were satisfied averagely, confident claimants were satisfied more than averagely, and socially isolated claimants were satisfied less than averagely on the variables mentioned above.

For all other variables, no significant differences between claimant types in opinions about behaviour and satisfaction were found, and too few complaints were filed to establish differences between the claimant types. In other words, it seemed that-in the current sample-most of the opinions about the assessment interview were not determined by claimants' intentions, attitudes, social influence, self-efficacy, skills, obstacles, and support, but by other aspects (such as the physician).

\section{Discussion}

\section{Main Findings}

Three types of claimants could be distinguished. These three types were: (A) claimants with negative expectations about their skills and a high intention to accept social support as well as high actual support, named the 'insecure support-seeking'; (B) claimants with reasonably to high social support, low intentions to accept support, and good skills for the interview, named the 'confident'; and (C) claimants with moderate skills and lacking social support, named the 'socially isolated'. On average all claimants were satisfied with the communication with physicians during a recently attended medical disability assessment interview. Of the three types, insecure support-seeking claimants were averagely satisfied, and confident claimants were even more than averagely satisfied. However, socially isolated claimants were less satisfied, especially with regard to how the physician expressed his or her opinions about work abilities, listening behaviour, and information exchange. Nonetheless, on most variables satisfaction did not differ between the three types of claimants. In other words, for these variables satisfaction was not determined by claimants' intentions, attitudes, social influence, selfefficacy, skills, obstacles, and support, but by other aspects.

\section{Findings in Relation to Other Studies}

Many different typologies of patients have parallels with our three types. For example, Flynn et al. [12] categorised people into four distinct types based on preferences concerning participation in medical decision making with regard to deliberateness and autonomy. Differences between our three types of claimants seem related to this autonomy. That is, insecure support-seeking claimants are high on their intentions to get social support and on availability of social support, and thus are less autonomous, while both other types turn to social support less frequently. The dimension of deliberateness, i.e. the need to be offered choices, could be considered parallel to the distinction between passive and active coping. This would imply that confident claimants show the most need to explore the choices, while insecure support-seeking and socially isolated claimants have the need to look for confirmation of their own choices instead of exploring choices.

Boot et al. [13] classified employees with asthma and COPD based on their attitudes, coping with disabilities, views about revealing limitations to others, and other variables, in four groups: adjusted workers, cautious workers, eager workers, and worried workers. Adjusted workers resemble confident claimants, because they accept their limitations, are not overly preoccupied with their 


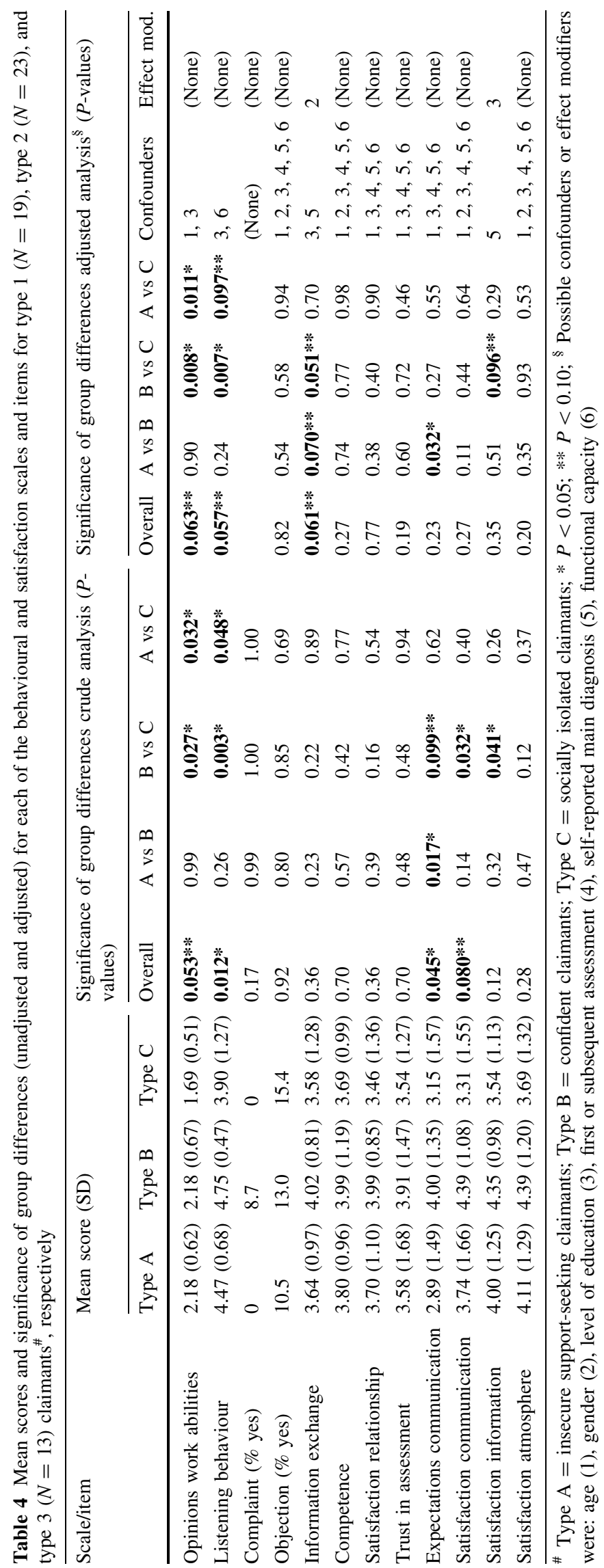


emotions, and have a strong need for control. Eager workers also resemble confident claimants, mostly because they are highly motivated. Cautious workers are worried about their health and try to prevent limitations, and therefore bear the most resemblance to insecure supportseeking claimants. Worried workers show similarities with cautious workers. They resemble both insecure supportseeking claimants and socially isolated claimants, because they have negative expectations, feel adequately supported, but face their limitations.

Guck et al. [14] developed a psychosocial typology of diabetic patients. They included social support and selfefficacy as possible cluster variables. Their results showed three types of diabetic patients: spousal over-involvement patients, adaptive coping patients, and low support/ low involvement patients. The spousal over-involvement patients bear resemblance to our insecure support-seeking claimants, because social support is highly available to them, but they lack options to autonomously handle situations. The adaptive coping patients appear similar to the confident claimant. The low support/low involvement patients bear the most resemblance to our socially isolated claimants, although the low involvement aspect is also presented in the confident claimants. These parallels of our results with those of studies categorising other patients on other variables strengthen the plausibility of our typology.

\section{Strengths and Limitations of the Study}

The strengths of this study were that: (1) the typology of claimants was developed based on self-reports of claimants (not on stereotypes of social insurance physicians); (2) all scales used in the cluster analysis were selected-before starting the cluster analysis-based on their relevance for medical disability assessments; (3) several variables of behaviour and satisfaction were included in the study; (4) data were collected at two successive moments in time; and (5) a theoretical model, the ASE model, was taken as a starting point. With regard to the fourth strength, i.e. the collection of data at two points in time, it was important that the questionnaire from which the claimant types were extracted, was completed prior to the actual assessment interview that the second questionnaire asked about. Because of this, no bias from that assessment interview could have occurred in the classification.

The first limitation of this study was the limited number of participants and the finding that claimants for a subsequent assessment and older claimants were more willing to participate in the study (selection bias). A non-response analysis could not be performed, but reasons not to participate might have been: almost simultaneously receiving the first questionnaire and having to attend the assessment interview (i.e. limited time to complete the first questionnaire), and fear of the consequences of participating for the social security benefit (although claimants were explicitly told that the social insurance physician would not be informed about their participation and participation would not influence their chances for a benefit). The second limitation of this study is that cluster analysis does not differentiate between relevant and irrelevant variables: it just divides the participants in the most consistent clusters, based on all the variables the researcher puts in the analysis. The method is thus sensitive to take into account irrelevant variables. It was attempted to overcome this limitation by starting from the theoretical perspective of the ASE model and by pilot testing our questionnaires for relevance of the questions. In addition, the types were discussed in group interviews with social insurance physicians to check their face validity.

\section{Implications for Practice and Future Research}

The results imply that, to cover the majority of the claimants, at least three scenarios for actors enacting medical disability claimants in role playing should be made. These three scenarios should be based on the insecure support-seeking claimant, the confident claimant, and the socially isolated claimant. Of course, within these three types of claimants differences exist, which means more scenarios are possible regarding the same 'basic' type. In addition, future research should focus on the relationship between the types of claimants and the most effective physician communication styles, as well as possibilities for changing claimant behaviour by the social insurance physician.

The findings with regard to differences in satisfaction between the three claimant types imply that special attention should be paid to socially isolated claimants in communication training. In contrast, it is unlikely that paying special attention to confident claimants will result in more satisfaction, because they were satisfied already. This also applies to insecure support-seeking claimants, because they were rather satisfied on most variables as well. Furthermore, findings indicate that satisfaction with the communication might often not be determined by claimants' intentions, attitudes, social influence, self-efficacy, skills, obstacles, and support regarding the communication, but by other variables. Most likely, those variables concern the interview itself, such as the physician who performs the interview and his/her communication style. Therefore, it may be inferred that claimants are able to give a differentiated opinion about the communication during an assessment interview, despite the large implications of the outcome of the assessment. Due to the relatively low number of participants in this study, carefulness with regard to these implications is required and future studies 
with a larger population are warranted to be able to draw stronger conclusions.

From the claimant classification several directives can be deduced for social insurance physicians to match their communication styles to claimants' preferences. As noted above, special attention should be paid to socially isolated claimants, because these were the least satisfied claimants. The physician should especially mind his/her sharing of opinions regarding work ability, listening behaviour, and the information exchange. Furthermore, socially isolated claimants may feel a need to elaborate extensively on their personal and working situation, especially at the beginning of the interview. The social insurance physician might want to give these claimants an opportunity to elaborate initially, therewith preventing unnecessary dwelling further on.

We successfully classified claimants in types of people with comparable characteristics. However, of course also differences exist between claimants of the same type and there will be claimants who do not fit exactly within one of the three types. Therefore, it is important that social insurance physicians also stay aware of individual differences between claimants when using the results of this study in practice. This way, possible negative effects of stereotyping, such as overestimated uniformity and rigid expectations, can be avoided. Individual differences considered, complying with directives for matching communication styles to claimants' needs might facilitate a better claimant-physician relationship and a more effective information exchange. However, research is needed to test this assumption. Additionally, future research should focus on the effects and possible difficulties of using the claimant types for role play scripts in communication skills training for physicians.

\section{Conclusion}

Three types of claimants could be distinguished: (A) insecure support-seeking claimants; (B) confident claimants; and (C) socially isolated claimants. The types could be used for role play scenarios. Although on most variables satisfaction did not differ between the types of claimants, especially regarding the sharing of opinions about work abilities, listening behaviour of the physician, and information exchange confident claimants were highly satisfied, socially isolated claimants were unsatisfied, and insecure support-seeking claimants were averagely satisfied. Therefore, in communication training special attention should be given to recognising socially isolated claimants and communicating with them.

Acknowledgments The authors thank everyone involved in this study. Especially, Marianne Berkhof, MSc, for her assistance in collecting the data for this paper and preparing it for analysis, all claimants who participated in this study, and the people of the Institute of Employee Benefit Schemes who assisted in collecting demographic and background data.

This research project is funded by the Dutch 'Stichting Instituut Gak', a foundation that initializes and supports innovative projects in the Dutch social security sector, and is supported by the Dutch Institute of Employee Benefit Schemes (UWV). The authors have no conflicts of interest that are directly relevant to the content of this article.

\section{References}

1. Berkhof M, Van Rijssen HJ, Schellart AJM, Anema JR, Van der Beek AJ. Effective training strategies for teaching communication skills to physicians: an overview of systematic reviews. Patient Educ Couns. 2010. (in press).

2. Aylward M, Sawney R. Disability assessment medicine combines aspects of occupational medicine with insurance and social security medicine. BMJ. 1999;318:2.

3. De Boer WEL, Besseling JJM, Willems JHBM. Organisation of disability evaluation in 15 countries. Prat Organ Soins. 2007; 38:205-17.

4. De Boer WEL, Wijers JHL, Spanjer J, van der Beijl I, Zuidam W, Venema A. Models for interviewing in insurance medicine. Tijdschr Bedrijfs Verzekeringsgkd. 2006;14:17-23.

5. Willems S, De Maesschalck S, Deveugele M, Derese A, de Maeseneer J. Socio-economic status of the patient and doctorpatient communication: does it make a difference? Patient Educ Couns. 2005;56:139-46.

6. Epstein RM. Making communication research matter: what do patients notice, what do patients want, and what do patients need? Patient Educ Couns. 2006;60:272-8.

7. De Vries H, Dijkstra M, Kuhlman P. Self-efficacy: the third factor besides attitude and subjective norm as a predictor of behavioral intention. Health Educ Res. 1988;3:273-82.

8. Ajzen I, Madden TJ. Prediction of goal-directed behavior: attitudes, intentions and percieved behavioral control. J Exp Soc Psychol. 1986;22:453-74.

9. Ajzen J. The theory of planned behavior. Organ Behav Hum Decis Process. 1991;50:179-211.

10. Steiner DL, Norman GR. Health measurement scales, a practical guide to their development and use. 4th ed. New York: Oxford University Press; 2008.

11. Hair JF, Tatham RL, Anderson RE, Black W. Multivariate data analysis. 5th ed. New Jersey: Prentice-Hall Inc; 1998.

12. Flynn KE, Smith MA, Vanness D. A typology of preferences for participation in healthcare decision making. Soc Sci Med. 2006;63:1158-69.

13. Boot CRL, van Exel NJA, van der Gulden JWJ. "My lung disease won't go away, it's there to stay": profiles of adaptation to functional limitations in workers with asthma and COPD. J Occup Rehabil. 2009;19:284-92.

14. Guck TP, Banfield MA, Tran SM, Levy JF, Goodman MD, Barone EJ, et al. A psychosocial taxonomy of patients with diabetes: validation in a primary care setting. Diabet Med. 2008;25:716-21.

15. Bramsen I, Bleiker EMA, Triemstra AHM, van Rossum SG, van der Ploeg HM. A Dutch adaptation of the Ways of Coping Questionnaire: factor structure and psychometric properties. Anxiety Stress Coping. 1995;8:337-52.

16. Schreurs PJG, van de Willige G. Coping with problems and events. Lisse: Swets \& Zeitlinger; 1988.

17. Carver CS, Scheier MF, Weintraub JK. Assessing coping strategies: a theoretically based approach. J Pers Soc Psychol. 1989; 56:267-83. 
18. Van der Bij AK, De Weerd S, Cikot RJLM, Steegers EAP, Braspenning JCC. Validation of the Dutch short form of the state scale of the Spielberger State-Trait Anxiety Inventory: considerations for usage in screening outcomes. Community Genet. 2003;6:84-7.

19. Schwarzer R. Self-regulatory processes in the adoption and maintenance of health behaviors. The role of optimism, goals, and threats. J Health Psychol. 1999;4:115-27.

20. Pearlin LI, Schooler C. The structure of coping. J Health Soc Behav. 1978;19:2-21.

21. Croon NHTh, Langius SWTh. [Work and health. A study about the practices in insurance medicine at the work insurance boards]. PhD Thesis. Amsterdam: University of Amsterdam, Institute for Social Medicine, 1993.

22. Van der Burg CL. [Client monitor regarding client-centeredness of the insurance physician and labour expert during disability assessments (published internally)]. Amsterdam, The Netherlands: Institute of Employee Benefit Schemes, 2007.
23. Van der Feltz-Cornelis C, Van Oppen P, Van Marwijk HWJ, De Beurs E, Van Dyck R. A patient-doctor relationship questionnaire (PDRQ-9) in primary care: development and psychometric evaluation. Gen Hosp Psychiatry. 2004;26:115-20.

24. Verbeek J, Van Dijk F, Rasanen K, Piirainen H, Kankaanpaa E, Hulshof C. Consumer satisfaction with occupational health services: should it be measured? Occup Environ Med. 2001;58: $272-8$.

25. Verbeek JH, De Boer AG, Van der Weide WE, Piirainen H, Anema JR, Van Amstel RJ, et al. Patient satisfaction with occupational health physicians, development of a questionnaire. Occup Environ Med. 2005;62:119-23.

26. Nauta AP, Von Grumbkow J. Factors predicting trust between GPs and OPs. Int J Integr Care. 2001;1:e31.

27. Nauta AP. [A matter of confidence? About cooperation of general practitioners and occupational physicians]. PhD Thesis. Heerlen: Open University of the Netherlands, 2004. 